\title{
Continuidades y rupturas en la Ley de Educación de la provincia de Buenos Aires (1875-1995) ${ }^{1}$
}

\author{
Continuities and ruptures in the education act of the province of Buenos \\ Aires (1875-1995)
}

Continuidades e rupturas na Lei de Educação do estado de Buenos Aires (1875-1995)

Eva Mara Petitti ${ }^{2}$

Centro de Investigación y Transferencia de la provincia de Entre Ríos

Universidad Nacional de Entre Ríos (Argentina)

Recepción: 11/01/2017

Evaluación: 24/04/2015

Aceptación: 05/05/2017

Artículo de Reflexión

DOI: https://doi.org/10.19053/01227238.5546

\section{RESUMEN}

Este artículo realiza un recorrido histórico de la Ley de Educación de la provincia de Buenos Aires entre su sanción en 1875 y las reformas de 1951 y 1995, con el fin de responder por qué el derrocamiento del gobierno peronista en 1955, que es considerado -por los propios actores y las ciencias sociales- un punto de quiebre en la periodización de la historia de la educación argentina, no implicó la promulgación de una nueva ley. Para ello se analizan los distintos textos de la Ley de Educación que fueron aprobados en 1875 , 1951 y 1995, las modificaciones parciales, los proyectos de reforma que no llegaron a ser sancionados y los debates en la legislatura bonaerense que se realizaron al respecto. Se observa que las reformas a la ley coincidieron con cambios profundos en los objetos de legislación que se dieron en el marco de transformaciones en el Estado argentino. Por lo tanto, se concluye

1 Este artículo forma parte del proyecto de investigación titulado "La educación primaria y el Estado durante los años ‘60. Un estudio de las políticas y las prácticas escolares en la provincia de Buenos Aires” financiado por el Consejo Nacional de Investigaciones Científicas y Técnicas (CONICET) de Argentina.

2 Doctora en Historia por la Universidad Nacional de Mar del Plata. Investigadora Asistente del Consejo Nacional de Investigaciones Científicas y Técnicas de Argentina. Email: marapetitti@yahoo.com.ar 
que es posible cuestionar los alcances de tomar el derrocamiento del gobierno peronista en 1955 como un punto de quiebre en la periodización de la Historia de la Educación Argentina.

Palabras clave: Revista Historia de la Educación Latinoamericana, Política, Legislación, Educación, Provincia de Buenos Aires.

\section{ABSTRACT}

This article follows a historical track of the Education Act of the province of Buenos Aires between its sanction in 1875 and the reforms of 1951 and 1995, in order to answer why the overthrow of the Peronist government in 1955, which is considered - by the actors themselves and the social sciences- as a turning point in the periodization of history of education in Argentina, did not imply the enactment of a new law. For this purpose, they were analyzed various texts of the Education Law that were approved in 1875, 1951 and 1995, the partial amendments, the reform projects that were not sanctioned and the debates in the Buenos Aires legislature that were carried out in this regard.

It is observed that the reforms to the law coincided with profound changes in the objects of legislation that occurred within the framework of transformations in the Argentine State. Therefore, it is concluded that it is possible to question the scope of assuming the overthrow of the Peronist government in 1955 as a turning point in the periodization of the History of Education in Argentina.

Keywords: Journal History of Latin American Education, Politics, Legislation, Education, Buenos Aires Province.

\section{RESUMO}

Este artigo realiza um resgate histórico da Lei de Educação do estado de Buenos Aires entre sua sanção em 1875 e as reformas de 1951 e 1995, com a finalidade de responder por que a queda do governo peronista em 1955, considerado - pelos próprios atores e pelas ciências sociais uma ruptura na periodização da história da educação argentina, não implicou a promulgação de uma nova lei. Para isso foram analisados os distintos textos da Lei de Educação que foram aprovados em 1875, 1951 e 1995, as modificações parciais, os projetos de reforma que não chegaram a ser sancionados e os debates na legislatura bonaerense que foram realizadas a respeito. Observa-se que as reformas à lei coincidiram com mudanças profundas nos objetos da legislação que se deram no marco das transformações no Estado argentino. Portanto, concluise que é possível questionar os alcances de tomar a queda do governo peronista em 1955 como um ponto de quebra na periodização da História da Educação Argentina.

Palavras-chave: Revista História da Educação Latino-americana - Política Legislação - Educação - Província de Buenos Aires. 


\section{INTRODUCCIÓN}

El objetivo de este trabajo consiste en examinar los alcances de tomar el derrocamiento del gobierno peronista en 1955 como un punto de quiebre en la periodización de la historia de la educación argentina desde la perspectiva de la acción estatal. Mónica Rein dio sugerentes elementos al examinar los puntos de continuidad del periodo 1946-1962, pero focalizó su análisis en las políticas de adoctrinamiento. ${ }^{3}$

Aun cuando el problema de la periodización histórica es siempre discutible, señala José Carlos Chiaramonte, la tendencia a dividir la Historia en segmentos cronológicos persiste. ${ }^{4}$ Cabe señalar en relación a esta cuestión, coincidiendo con Vilfredo Avalo Viamontes que: "A pesar de las limitaciones propias a todo corte histórico, este representa una verdad más profunda que la visión lineal del progreso humano." ${ }^{5}$

A mediados de los años '90 Rubén Cuccuza advertía que en general, las periodizaciones de la historia de la educación argentina se mantenían "aferradas a las periodizaciones políticas"6 y agregaba que, aunque compuesta por fechas, una periodización implica la construcción de una propuesta teórica por encontrar respuestas al sentido de la historia." ${ }^{\prime 7}$ A partir de entonces, numerosos trabajos han cuestionado el traslado de la periodización de la historia social y política a la historia de la educación ya que los mismos atan "a los procesos institucionales a través de una correspondencia fuerte entre la política educativa y la práctica escolar" ${ }^{\prime \prime}$ y por lo tanto se tornan completamente artificiales en la revisión de los movimientos pedagógicos y las innovaciones didácticas si no son revisadas a la luz de la lógica propia de las actuaciones escolares. ${ }^{9}$ Como ha señalado Elisie Rockwell "la experiencia escolar siempre ha sido mas bien heterogénea, desfasada en el tiempo, cruzada por las biografías particulares" ${ }^{\prime 10}$ y por lo tanto difícil de medir con los parámetros de la historia política.

Siguiendo esta línea, un importante aporte en el sentido de cuestionar 1955 como un punto de quiebre en la historia de la educación argentina, lo constituye la tesis doctoral de Silvia Castillo. La autora con base en un extenso y nutrido corpus de fuentes, indaga acerca de los límites de la "desperonización" en el plano de

3 Mónica Rein, Politics and Education in Argentina, 1946-1962, (Nueva York: M.E. Sharpe, 1998).

4 José Carlos Chiaramonte, "La historia intelectual y el riesgo de las periodizaciones" Prismas, Revista de historia intelectual, No. 11, (2007): 190.

5 Vilfredo Avalo Viamontes "Evolución de la escuela rural en Cuba en los siglos XIX y XX" Revista historia de la educación latinoamericana 18, No. 26 (2016): 91-112.

6 Rubén Cuccuza “Continuidades y rupturas el problema de las periodizaciones", Anuario SAHE, No. 1 (1996): 24.

7 Rubén Cuccuza “Continuidades y rupturas el problema de las periodizaciones”, Anuario SAHE, No. 1(1996): 27.

8 Mariano Narodowski "La utilización de periodizaciones macropolíticas en la historia de la educación. Algunos problemas", en Escuela, historia y poder. Miradas desde América Latina, eds. Martínez Boom y Mariano Narodowski (Buenos Aires: Ediciones Novedades Educativas, 1996), 150.

9 Marina Smeja y Magaldy Téllez. "Una mirada crítica a las prácticas discursivas dominantes en el campo de la historia de la educación en Venezuela”, en Escuela, historia y poder. Miradas desde América Latina, eds. Alberto Martínez Boom y Mariano Narodowski (Buenos Aires: Ediciones Novedades Educativas, 1996), Agustín Adúriz Bravo, "Hacia la especificidad de la historia de la educación en un abordaje transdisciplinar", Revista Latinoamericana de Estudios Educativos (México), Vol. 31, No. 2, (2001): 59-68.

10 Elsie Rockwell, Hacer escuela, hacer estado. La educación posrevolucionaria vista desde Tlaxcala. (México: CIESAS, 2007 ), 30. 
las prácticas docentes. ${ }^{11}$ En cambio, las investigaciones que abordan los aspectos normativos y estructural-formales de los sistemas educativos toman como base la periodización realizada desde los estudios sociopolíticos. ${ }^{12}$ De hecho, buena parte de las investigaciones sobre historia de la educación argentina que incluyen el nivel elemental, se inician o finalizan con el golpe de Estado de 1955. ${ }^{13}$

Ahora bien, en los últimos años se ha puesto en cuestión el consenso existente en la historiografía argentina en considerar 1955 como un punto de quiebre en la política argentina. Omar Acha y Nicolás Quiroga proponen evitar el encapsulamiento del peronismo en su década fundacional, que concluiría en septiembre de 1955, aunque señalan que respecto a las políticas estatales la caída de Perón marca una ruptura radical. ${ }^{14}$ Avanzando en esta línea, Patricia Berrotarán y Elsa Pereyra plantean una periodización que identifica tres grandes momentos "instituyentes" del Estado argentino: el motorizado desde 1862, que recibe un definido impulso en manos de la denominada "generación del ' 80 "; el iniciado por el peronismo clásico; y el correspondiente al menemismo. Las autoras señalan que cada uno de estos momentos inauguró una forma de estado, si bien dentro de estas grandes etapas, se hayan contenidos periodos transicionales, tales como la década del 30 o los años de la última dictadura militar. ${ }^{15}$ En concordancia, la Colección de Historia de la provincia de Buenos Aires toma el advenimiento del peronismo como acontecimiento demarcatorio de los dos tomos que se ocupan del siglo XX. Como enfatiza Manuel Palacio, director de la Colección, ese corte supone una hipótesis "que además va a contracorriente con una cronología demasiado asentada entre nosotros", según la cual con el advenimiento del peronismo, "se producen cambios decisivos que rompen con el pasado de una manera más clara que la crisis de 1930."16

En este camino analítico intenta inscribirse este artículo, que se interesa particularmente por el área de la educación desde la perspectiva de la acción estatal, con el objetivo de repensar el impacto de la caída del peronismo y las medidas "desperonizadoras" en las transformaciones que este implicó en materia educativa. Para ello se analizan los distintos textos de la Ley de Educación que fueron aprobados en 1875, 1951 y 1995, las modificaciones parciales, los proyectos de reforma que no llegaron a ser sancionados y los debates en la legislatura bonaerense que se realizaron

11 Silvia Castillo "Las políticas y las prácticas educativas del magisterio pampeano (1958-1966)" (tesis de Doctorado en Facultad de Ciencias Humanas, Universidad Nacional del Centro, 2013).

12 Agustín Adúriz Bravo, "Hacia la especificidad de la historia de la educación en un abordaje transdisciplinar", Revista Latinoamericana de Estudios Educativos (México), Vol. 31, No. 2, (2001): 59-68.

13 La mayor parte de los trabajos de Historia de la Educación concluyen o en 1955. Ver entre otros, Sandra Carli, Niñez, pedagogía y politica. Transformaciones de los discursos acerca de la infancia en la historia de la educación argentina entre 1880 y 1955 (Buenos Aires: Miño y Dávila, 2002); Talía Gutiérrez Educación, agro y sociedad; políticas educativas agrarias en la región pampeana, 18971955 (Buenos Aires: Universidad Nacional de Quilmes, 2007); Rubén Cucuzza (dir.) y Pablo Pineau (codir.) Para una historia de la enseñanza de la lectura y escritura en Argentina. Del catecismo colonial a La Razón de mi Vida (Buenos Aires: Miño y Dávila, 2002); Adriana Puiggrós (dir.) Dictaduras y utopías en la historia reciente de la educación argentina (1955-1983) (Buenos Aires: Editorial Galerna, 1997); Cecilia Braslavsky La educación argentina (1955-1980) (Buenos Aires: CEAL, 1980); Romina de Luca, Brutos y Baratos. Descentralizacion y privatización en la educación argentina (1955-2001) (Buenos Aires: ediciones RyR, 2008).

14 Omar Acha, y Nicolás Quiroga, El hecho maldito. Conversaciones para otra historia del peronismo (Rosario: Prohistoria, 2012 ), 42.

15 Patricia Berrotarán y Elsa Pereyra "Momentos y Procesos para una historia del Estado en Argentina", Revista Aportes para el Estado y la administración gubernamental. Buenos Aires, 18, No. 30 (2012).

16 Palacio, Juan Manuel "Prólogo", Historia de la provincia de Buenos Aires. De la federalización de Buenos Aires al advenimiento del peronismo (1880-1943) (La Plata: Unipe/Edhasa, 2013), 9. 
al respecto. Se trata de la legislación de mayor nivel que regula la política educativa de la provincia y de la primera ley de educación Argentina, cuyo texto fue reformado en su totalidad en tres ocasiones: el gobierno de Juan Domingo Perón en 1951, el de Carlos Menem en 1995 y el de Néstor Kirchner en 2006.

Elsie Rockwell, señala que "las leyes no son simples representaciones de la realidad escolar en el periodo de su vigencia, aunque pueden reflejar, tangencialmente, las preocupaciones y pugnas coyunturales." Para ver reflejadas esas preocupaciones y pugnas, que interesa al presente trabajo, "hay que indagar cómo se generaron las leyes por determinados grupos, imaginar cómo se legitimaron y cómo se entendieron en coyunturas políticas precisas y observar cómo se utilizaron para normar o reformar las escuelas." ${ }^{17}$ Estudiar los cambios en la legislación educativa permite analizar de qué manera fue variando a lo largo del tiempo la concepción acerca de la obligatoriedad escolar, el lugar de la sociedad civil, el peso de la Iglesia católica, la orientación de la educación y el rol que asumió el Estado.

¿Por qué la Ley de Educación sancionada durante el peronismo no se modificó en 1955 teniendo en cuenta que hubo un fuerte rechazo a la misma por parte de la oposición política que luego de 1955 brindó apoyo político al nuevo gobierno? ${ }^{18}$ ¿Por qué no se reformó en 1958 cuando asumió el gobierno constitucional, sino que por el contrario se mantuvo durante los siguientes gobiernos antiperonistas -civiles y militares-y se reformó recién en 1995? Con el objeto de responder estos interrogantes, el presente artículo se divide en dos partes. La primera analiza desde la sanción de la Ley de Educación Común en 1875 hasta el triunfo electoral del peronismo, teniendo en cuenta las reformas que se realizaron y los proyectos que se presentaron a lo largo del periodo. En la segunda parte, estudiamos los debates que precedieron la Ley de Educación de 1951, así como los intentos infructuosos para modificarla con posterioridad al derrocamiento del gobierno peronista.

A fin de delimitar el espacio de esta exploración tomamos una experiencia provincial porque constitucionalmente se trata del principal ámbito de gestión de la escuela primaria. Aunque la provincia de Buenos Aires representa una experiencia particular en el régimen federal, resulta difícil exagerar la importancia que supone para el país, tanto por su peso demográfico, económico y político como por las dimensiones de su sistema educativo.

\section{La Ley de 1875 y los proyectos de reforma}

A la luz de la Constitución Nacional de 1853 que cedió la obligación de impulsar la educación primaria a las provincias, la de Buenos Aires en su carta orgánica de 1873, estableció que la legislatura dictaría las leyes necesarias para establecer y organizar un sistema de educación común, a la vez que proporcionó una serie de reglas a las

17 Elsie Rockwell, Hacer escuela, hacer estado. La educación posrevolucionaria vista desde Tlaxcala. (México: CIESAS, 2007), 122.

18 Como señala Estela Spinelli, "durante la instauración de gobiernos de facto en la Argentina, con el triunfo del golpe antiperonista desde septiembre de 1955 hasta la salida electoral de febrero de 1958, los partidos políticos tuvieron injerencia directa en el diseño y en la toma de decisiones políticas." Ver Estela Spinelli Los vencedores vencidos. El antiperonismo y la "Revolución Libertadora" (Buenos Aires: Biblos, 2005), 131. 
cuales debían sujetarse tales leyes, que definían la obligatoriedad y gratuidad de la educación común, el gobierno escolar -conformado por una Dirección General de Escuelas, un Consejo General de Educación y Consejos Escolares de Distrito- y la forma de administración de los recursos. ${ }^{19}$

Sobre la base constitucional, en 1875 la provincia de Buenos Aires sancionó la Ley de Educación Común, con el número 988. Su aprobación no estuvo exenta de debates sobre el carácter obligatorio, la duración de la obligatoriedad y las atribuciones de los Consejos Escolares de distrito. ${ }^{20}$ Quedó estructurada en cinco partes que referían a la obligatoriedad de la educación primaria; la dirección y administración del gobierno educativo; los directores y maestros; las fuentes y administración de los recursos y las bibliotecas populares. En cambio, los aspectos relacionados con los contenidos y el funcionamiento de las escuelas fueron determinados por el Reglamento de Escuelas, que se sancionó al año siguiente. A partir de entonces las niñas que tenían entre seis y 12 años de edad y los niños de seis a 14, pasaron a ser comprendidos por la obligatoriedad y gratuidad de la ley.

Resultado de los debates, desde el punto de vista organizativo permaneció en el texto de la ley el ideario de José Manuel Estrada y Domingo Faustino Sarmiento, quien ocuparía el cargo de Director General de Escuelas de la provincia entre 1875 y 1881. Así, a la vez que se importó al escenario bonaerense la estructura norteamericana de participación civil en el control de la institución escolar a través de los Consejos Escolares cuyos miembros debían ser elegidos por los vecinos en los comicios municipales, las facultades técnicas y administrativas de estos, quedaron compartidas con la Dirección General de Escuelas y el Consejo General -presidido por el director general e integrado por ocho vocales cuyos cargos duraban cuatro años pudiendo ser reelectos-, dando lugar a una organización que al estilo francés, centralizaba las decisiones de la provincia. La elección de las autoridades de la Dirección y el Consejo General se realizaba con el acuerdo que las Cámaras de Senadores y Diputados respectivamente brindaran al Poder Ejecutivo.

Con el objetivo de procurarle al gobierno educativo autonomía financiera respecto del poder político, las escuelas se sostendrían con recursos propios (producto de multa que no tuviera aplicación determinada por la ley, los bienes que por falta de herederos correspondiesen al fisco, las donaciones de particulares y del Congreso Nacional), constituyendo una renta escolar.

La Ley 988, establecía que la educación primaria debía "formar el carácter de los hombres por la enseñanza de la religión y de las instituciones republicanas", entendiendo que el Consejo General de Educación estaba obligado a respetar en la organización de la enseñanza religiosa las creencias de los padres de familia, ajenos a la comunidad católica. Posteriormente a la sanción de la Ley 1420 de Educación Común de la Nación y al desplazamiento del grupo católico liberal liderado por Estrada, en 1890 la Dirección General de Escuelas emitió una resolución que eliminaba

19 Constitución de la Nación Argentina 1853, Art. 205.

20 Ver Provincia de Buenos Aires, Diario de Sesiones de la Cámara de Diputados, [en adelante PBADSCD], 1874, 203-206. Para un análisis de los debates previos a la sanción de la Ley, ver Enrique Barba "La ley de educación común de Buenos Aires de 1875", Trabajos y Comunicaciones, 18 (1968): 53-65. 
la enseñanza religiosa en horario de clase. ${ }^{21}$ A partir de esa normativa la enseñanza religiosa solo podría ser dictada a contra turno una vez por semana en las escuelas comunes, por los ministros de cada culto, quedando prohibido al personal docente tomar en ella participación alguna. Para ello los padres debían manifestar por escrito su consentimiento al director de escuelas. ${ }^{22}$

En 1905, durante la gestión conservadora del gobernador Marcelino Ugarte, tuvo lugar una reforma parcial de La ley de Educación Común de la provincia de Buenos Aires. ${ }^{23}$ La misma implicó dos modificaciones que impactaron en la educación de la provincia de Buenos Aires.

En primer lugar, bajo pena de suspender por un año al director que lo permitiera "ningún niño podrá ser alumno de una escuela pública antes de haber cumplido ocho años, ni después de cumplir doce" versaba el texto de la normativa sancionada en 1905. ${ }^{24}$ Así, la obligatoriedad escolar se reducía a las escuelas primarias elementales, es decir, a aquellas que tenían desde primero inferior hasta tercer grado. Las escuelas primarias superiores que enseñaban hasta sexto grado, a partir de ese momento fueron denominadas complementarias, pasaron a ser opcionales y dejaron de estar financiadas por rentas escolares. ${ }^{25}$ De esta forma, triunfaba aquella concepción que entendía a la escuela como una institución encargada de brindar el mínimo de instrucción necesaria.

El argumento para esta reducción consistía en "la esterilidad de sus resultados", refiriéndose en esos términos a que apenas un $2 \%$ de la población escolar terminaba sexto grado y a que era escasa la disminución del analfabetismo en relación a los recursos invertidos. Los propulsores de la ley, limitaban la obligatoriedad y por lo tanto la gratuidad de la escolaridad primaria a cuatro años, ya que sostenían que ese era el período en que concurrían los alumnos, tomando la ausencia y la deserción como resultado del desinterés de la población. Al reducir la obligatoriedad escolar, los recursos escolares en lugar de invertirse en las escuelas complementarias cuyo mantenimiento era más costoso, explicaban, se destinarían a crear más escuelas que

21 Pablo Pineau, La escolarización de la provincia de Buenos Aires (1875-1930), (Buenos Aires: Universidad de Buenos Aires, FLACSO, 1997), 57.

22 Provincia de Buenos Aires, Dirección General de Escuelas, Reglamento General de Escuelas, 1917 (1934), artículo 24.

23 A lo largo de esos treinta años se habían sancionado dos normativas que sentaron las bases del sistema educativo a nivel nacional. En 1884, cuatro años después de la federalización de la ciudad de Buenos Aires y en el marco de álgidas discusiones, se sancionó la Ley 1420, que regía para la ciudad de Buenos Aires y de los territorios nacionales. Establecía la educación común, obligatoria y gratuita para los niños y niñas de seis a 14 años y el gobierno de las escuelas de bajo control de un Consejo Nacional de Educación conformado por un presidente y cuatro vocales, a la vez que la administración local quedaba en manos de los Consejos Escolares elegidos por el Consejo Nacional de Educación. En 1905, durante la presidencia de Manuel Quintana, con el fundamento de complementar el sistema educativo provincial y suplir las carencias existentes, se sancionó la Ley Láinez que otorgaba al Consejo Nacional de Educación la facultad de establecer escuelas "en las provincias que lo solicitaran" -salvando así la inconstitucionalidad que podía suponer esta medida- teniendo en cuenta el porcentaje de analfabetos. Sobre la política educativa argentina entre 1870 y 1916, ver Lucía Lionetti La misión política de la escuela pública. Formar a los ciudadanos de la república (1870-1916) (Buenos Aires: Miño y Dávila, 2007).

24 Ley 2934, Registro Oficial de la Provincia de Buenos Aires, 14 de octubre de 1905

25 La división entre escuelas primarias elementales y superiores (o graduadas) fue realizada a partir de la sanción del Reglamento General de Escuelas, en 1876, al año siguiente de que fuera promulgada la Ley de Educación. En 1915 la Ley de Presupuesto reemplazó las escuelas complementarias por cursos complementarios que se anexaron a las escuelas elementales. Fue recién durante la intervención nacional, en septiembre de 1944, que se reformó la división entre escuelas comunes y complementarias que establecía el Reglamento General de Escuelas. Ver Provincia de Buenos Aires, Reglamento General para las Escuelas Públicas, vigente desde el 1 de septiembre de 1944, La Plata, Taller de Impresiones Oficiales, 1944; Revista de Instrucción Primaria, 1944, octubre, 16. 
tuvieran hasta tercer grado. ${ }^{26}$ El Director General de Escuelas Manuel Bahía, justificaba esta medida a un año de su aplicación utilizando un tono extremadamente crítico con respecto a la población escolar: "Así, se economizarán gastos para el hogar y para el Estado, y el niño se educará con hábitos permanentes de laboriosidad y puntualidad. (...) Antes el Estado tenía que cargar con el sostenimiento de maestros para los haraganes; ahora no entretiene párvulos y solamente admite haraganes cuando sobra espacio en la clase." 27

Ahora bien, ¿a qué se debió esta reforma que treinta años después de la primera normativa provincial reducía la obligatoriedad escolar? Mientras para Pablo Pineau implicó el reemplazo del imaginario civilizador, Lucía Lionetti considera que se asistió a un desplazamiento semántico del término que quedó asociado a una regeneración del orden social y moral. ${ }^{28}$ De todas formas, es posible que la medida atendiera también al déficit y el endeudamiento, que en esos años habían acortado seriamente los recursos de la provincia y en particular los de la Dirección General de Escuelas. ${ }^{29}$

En segundo lugar, esta reforma limitaba las funciones de los Consejos Escolares a la esfera administrativa. El interés por restringir las actividades de estos organismos había estado presente desde poco tiempo después de su fundación. En 1877 uno de sus principales propulsores expresaba que "en la práctica fallan los resultados, o faltan en muchas localidades vecinos que se interesen vivamente por el progreso de la educación, o no saben siempre cuáles son los medios de impulsarlas." ${ }^{30}$ Esto sumado a los cada vez más frecuentes proyectos destinados a limitar sus facultades, desencadenó en la reforma de 1905 que dejaba en manos de los Consejos las cuestiones administrativas en relación con los docentes y la comunidad -custodiar y conservar los bienes muebles e inmuebles, otorgar a los establecimientos escolares aquellos materiales necesarios para su buen funcionamiento-, así como a los aspectos materiales de las escuelas -tramitar pedidos o consultas que formulara el personal, fomentar la colaboración del vecindarios hacia la escuela e intervenir en los pagos que dispusiera el Ministerio-. En cambio, las funciones técnicas y políticas -inspeccionar, nombrar, contratar o dejar cesantes a los maestros, establecer nuevas escuelas y determinar su ubicación-, quedaron directamente a cargo de la Dirección General de Escuelas y el Consejo General de Educación. Estas modificaciones están relacionadas con la progresiva disminución de las atribuciones de los municipios, reducidas también a cuestiones administrativas. ${ }^{31}$

26 PBADSCD, 17 de agosto de 1905, 13 sesión ordinaria.

27 Manuel Bahía El gobierno escolar en la provincia de Buenos Aires (La Plata: Solá y Franco, 1906), 17.

28 Pablo Pineau, La escolarización de la provincia de Buenos Aires (1875-1930), (Buenos Aires: Universidad de Buenos Aires, FLACSO, 1997), 37 y Lucía Lionetti La misión política de la escuela pública. Formar a los ciudadanos de la república (1870-1916) (Buenos Aires: Miño y Dávila, 2007).

29 María Liliana Da Orden y Andrés Regalsky "Fiscalidad y organización estatal en la provincia de Buenos Aires (1880-1943)" en Historia de la provincia de Buenos Aires. De la federalización de Buenos Aires al advenimiento del peronismo, eds. Juan Manuel Palacio (Buenos Aires: Edhasa, 2013).

30 Domingo F. Sarmiento, Obras Completas, t. XLIV, p. 334. Citado en Juan Carlos Tedesco Educación y sociedad en la Argentina (18801945), (Buenos Aires: Siglo Veintiuno, 2003), 92.

31 Marcela Ternavasio "Municipio y política, un vínculo histórico conflictivo. La cuestión municipal en Argentina entre 1850 y 1920" (tesis de maestría, FLACSO, Buenos Aires, Argentina, 1991). Disponible en http://sala.clacso.org.ar/ [último acceso: marzo 2007] y Silvana Ferreyra y Mara Petitti "Populismo, instituciones locales y democracia (Provincia de Buenos Aires, 1945-1958)" Postdata. Revista de Reflexión y Análisis Político, 19, No. 2 (2014). 
Además de la reforma de 1905, la Ley de Educación tuvo algunas modificaciones en aspectos puntuales que no afectaron su contenido de fondo. En 1882 la Ley 1538 fijó en un $15 \%$ el porcentaje de las rentas que debían depositar trimestralmente las municipalidades; en 1911 la Ley 3397 reguló acerca de la liquidación de porcentajes de impuestos a las municipalidades; la Ley 3648 de 1916 derogó el artículo 39 que establecía que cada Juzgado de Paz se consideraría distrito escolar y en 1943, la Ley 5028 modificó el artículo 19 en lo que respecta a los mandatos de los Consejeros de Educación en caso que tuvieran que cubrir una vacante.

A partir del Golpe de Estado de 1930, la Iglesia católica ganó una creciente gravitación en la educación escolar, lo cual se expresó en un debate en la Convención Constituyente, entre quienes quería incluir los principios de la religión católica en los contenidos mínimos y quienes se opusieron a dicha innovación, resultando elegida la propuesta intermedia presentada por Manuel Fresco. ${ }^{32} \mathrm{Así}$ la Constitución de la provincia de Buenos Aires de 1934, además de incorporar aquellas reformas realizadas por la Ley de 1905, ${ }^{33}$ introdujo un artículo que establecía entre los fines de la educación común el de "formar el carácter de los niños en el culto de las instituciones patrias y en los principios de la moral cristiana, respetando la libertad de conciencia." ${ }^{34}$

Ante la reforma del texto constitucional y particularmente ante la incorporación de la enseñanza de la moral cristiana, se hacía necesario adecuar la Ley de Educación de 1875. Para ello en julio de 1935 se designó una comisión para que elaborara un nuevo plan que finalmente no fue aprobado. No obstante, durante la gobernación de Manuel Fresco se decretó y posteriormente se sancionó como ley (4755/39) la obligatoriedad de la enseñanza religiosa en las escuelas de la provincia de Buenos Aires. Esta medida fue resistida por el grupo conservador liderado por Rodolfo Moreno. Durante su gobernación (1942-1943) se conformó una nueva delegación que tomó a cargo la revisión completa del primitivo plan y elaboró un proyecto de ley Orgánica de Educación que el Poder Ejecutivo remitió en 1942 a la legislatura bonaerense para su sanción correspondiente, pero que tampoco fue aprobado.$^{35}$ En 1943 el ejército derrocó al gobierno nacional de Ramón Castillo, dando inicio a un proceso social y político que condujo al triunfo de Perón. Ese mismo año el Poder Ejecutivo Nacional sancionó el decreto que estableció la enseñanza religiosa. ${ }^{36}$

32 Manuel Fresco fue gobernador de la provincia de Buenos Aires entre 1936 y 1940.

33 Así incorporaba al inciso correspondiente al director general de escuelas la atribución de nombrar y remover a todo el personal técnico, administrativo y docente y en el apartado correspondiente a los consejos escolares especificaba que "La administración local y el gobierno inmediato de las escuelas en cuanto no afecte la parte técnica, estarán a cargo de consejos electivos de seis vecinos argentinos de cada partido de la Provincia. Las condiciones que deben reunir los electores serán las mismas que para elegir municipales y las condiciones de elegibilidad y formación de los consejos, serán las mismas de las municipalidades." Finalmente se añadía un artículo respecto a los recursos "Cuando la contribución escolar de un distrito no sea bastante para sufragar los gastos de educación del mismo, el Tesoro público llenará el déficit que resulte.”

34 Constitución de la provincia de Buenos Aires de 1934. Artículo 190. Ver además María Dolores Béjar "Altares y banderas en una educación popular: la propuesta del gobierno de Manuel Fresco en la provincia de Buenos Aires (1936-1940)" en Mitos, altares y fantasmas. Aspectos ideológicos de la historia del nacionalismo popular. (Buenos Aires: Estudios/Investigaciones núm. 12. Universidad Nacional de La Plata, 1992).

35 Anteproyecto de Ley Orgánica de Educación Común. Boletín Oficial de Educación. Abril, Dirección General de Escuelas de la provincia de Buenos Aires, 1946.

36 Véase Decreto-Ley 18.411/43 que en 1947 fue aprobado por el Congreso Nacional y sancionado como Ley 12.978/47. 
Durante el gobierno de la intervención designado en la provincia de Buenos Aires, en septiembre de 1944 se aprobó el proyecto del director General de Escuelas, Coronel Eduardo Noya, por el que se ampliaba la obligatoriedad escolar a siete años y se fijaba para el ingreso la edad mínima de seis, tanto para hombres como mujeres, dejando sin efecto la reforma de 1905. Poco tiempo antes se había eliminado la división entre escuelas comunes y complementarias que establecía el Reglamento General de Escuelas. ${ }^{37}$ Sin embargo, hubo que esperar hasta mayo de 1946 para que el Consejo General de Educación introdujera dicha modificación al Reglamento. ${ }^{38}$

En abril de 1946 volvió a presentarse otro proyecto de reforma a la Ley de Educación y se nombró una nueva comisión de funcionarios escolares para que lo estudiara. Este último, incorporaba la ampliación de la obligación escolar entre los seis y catorce años en un ciclo de siete grados, establecía un sistema rentístico propio y continuaba dando un lugar central a los aspectos del gobierno técnico y administrativo. En lo que respecta al gobierno local de las escuelas, mantenía la reforma de 1905 en cuanto establecía que la acción de los consejos escolares debía concentrarse en lo administrativo, sin afectar la parte técnica. ${ }^{39} \mathrm{~A}$ pesar que al igual que los anteriores no llegó a ser tratado, en 1946 se sancionó una normativa que ampliaba la obligatoriedad escolar, volviendo atrás la reforma de 1905.

\section{La Ley de Educación de 1951: peronismo y antiperonismo, continuidades y rupturas}

El triunfo del peronismo en las elecciones de 1946, en la provincia de Buenos Aires implicó el ascenso de Domingo Mercante, quien gobernó entre 1946 y 1952. Sus primeros años de gestión significaron importantes transformaciones en el marco de la Dirección General de Escuelas con la creación de nuevas dependencias que implicaron un proceso de diferenciación de las funciones de la Inspección General y de mayor especialización de las agencias que la componían. Así sus atribuciones, se extendieron más allá de la educación primaria incorporando la enseñanza preescolar, postescolar, especializada y la orientación profesional. Si bien desde 1946 se escucharon voces que proponían el reemplazo de la repartición autárquica por un Departamento de Estado, recién en 1949 con la reforma constitucional fue creado el Ministerio de Educación que sustituyó a la Dirección General de Escuelas y al Consejo General de Educación y reemplazó los Consejos Escolares por Delegaciones Administrativas.

En el mes de junio de 1951 el Poder Ejecutivo Provincial presentó en la legislatura un proyecto de la Ley de Educación, con el fin de reemplazar aquella sancionada en

37 Véase Reglamento General para las Escuelas Públicas, vigente desde el 1 de septiembre de 1944, La Plata, Taller de Impresiones Oficiales, 1944; Revista de Instrucción Primaria, 1944, octubre, 16.

38 Las modificaciones resueltas por el Consejo General de Educación e incorporadas al reglamento señalaban que "la obligatoriedad escolar alcanzará a todo niño que haya cumplido los 6 años al momento de inscribirse, debiendo extenderse su beneficio a los de menos edad y a los adolescentes en la medida y oportunidad que lo permitan los recursos de la provincia..." Véase "Fue modificado el reglamento general de escuelas de la Provincia de Buenos Aires." En Revista de Instrucción Primaria, 1946, mayo, 15. Según información oficial, mientras que en 1946 eran 784 las escuelas que extendían certificado hasta sexto grado, en 1952 ese número se había elevado a 2.200. Mensaje de Mercante al inaugurar las sesiones legislativas en 1952. PBADSCD, 1952, 36.

39 Anteproyecto de Ley orgánica de Educación Común. En Provincia de Buenos Aires, Dirección General de Escuelas, Boletín Oficial de Educación. Abril de 1946, año 9, número 79, La Plata. 
1875. A diferencia de los anteriores, modificaba en su totalidad a la anterior, al cambiar considerablemente los asuntos considerados objeto de legislación. La legislación, que sustituía a aquella sancionada 76 años antes, más que un punto de partida para transformar el sistema educativo, daba estabilidad legal a los cambios y expresaba los nuevos alcances del Estado. Por un lado, con base en lo establecido por la Constitución provincial de 1949, incorporó las reformas realizadas durante la gestión de Domingo Mercante -ampliación de las áreas de educación preescolar, postescolar y especial-, y dio un lugar central a los contenidos de enseñanza. Por otro lado, suprimió toda la legislación referente al gobierno autárquico reemplazado por el Ministerio de Educación y al financiamiento de la educación que desde 1946 comenzó a incluir las rentas generales en un porcentaje que se fue incrementando cada año, hasta representar hacia 1949 más del $80 \%$.

El debate sobre la Ley de Educación se desarrolló en una atmósfera propicia para la agudización de los discursos políticos. Como ha señalado Marcela Sebastiani, desde la victoria electoral de Perón en febrero de 1946, "el resentimiento entre sus partidarios y sus contrarios ha sido una de las características más recurrentes en la historia política argentina contemporánea." 40 La oposición al peronismo en el parlamento provino casi exclusivamente de la Unión Cívica Radical, con las excepciones de un diputado socialista electo en 1948 y un conservador en 1950. Si bien, como afirma Óscar Aelo, la legislatura de la provincia de Buenos Aires mostró una imagen civilizada en la realización de sus labores, el proyecto de ley de Educación se discutió en un contexto en que la polarización político partidaria a escala nacional se había intensificado. Fue en 1951, el año de la reelección de Perón. ${ }^{41}$

Luego de que el proyecto de ley fuera tratado por la Comisión de Culto, Instrucción y Educación Pública y antes de que se discutiera en la Cámara de Senadores, algunos diarios anticiparon la postura de los legisladores de la oposición. La prensa socialista expresaba que una vez sancionada la ley "las aulas argentinas se transformarán en laboratorios de experiencias políticas al servicio exclusivo de la clase gobernante" ${ }^{\prime 2}$ y el diario liberal La Nación publicaba que "El proyecto de ley en cuestión, entraña un peligro por los criterios de interpretación política e histórica que adopta, arbitrarios porque obedecen a conveniencias de partido (...) una de las características de la pedagogía totalitaria en la que Estado, partido y escuela son matices de una misma e inseparable realidad." 43

En ambas cámaras se establecieron largas discusiones sobre las características generales del proyecto de ley, sin repararse en las propuestas concretas. Para la Unión Cívica Radical el problema residía en “el espíritu que anima y preside esta ley

40 Marcela García Sebastiani "La otra cara de la Argentina peronista: radicales y socialistas en la oposición política a Perón (19461955)", en Fascismo y antifascismo. peronismo y antiperonismo. Conflictos políticos e ideológicos en la Argentina (1930-1955), ed. Marcela García Sebastiani (Madrid/Frankfurt: Vervuert, 2006),195. Este texto contiene un riguroso análisis acerca de cómo los radicales y socialistas manifestaron su oposición al gobierno peronista.

41 Aelo, Oscar El peronismo en la provincia de Buenos Aires (1946-1955) (Caseros: Eduntref, 2012), 105.

42 Anónimo, "Severa crítica al proyectado Estatuto del Docente hizo el diputado Bronzini." El Trabajo, Mar del Plata 2 de julio, 1951, 3. El diario socialista $E l$ Trabajo de la ciudad de Mar del Plata -con más de treinta años de trayectoria- trascendía el ámbito local y regional habida cuenta del cierre de La Vanguardia y del papel que desempeñaba Teodoro Bronzini, único miembro del partido que accedió a la legislatura en el período.

43 Anónimo. “Una Ley de Educación." Diario La Nación, ciudad de Buenos Aires, 17 de julio, 1951, 4. 
educacional." Por lo tanto, señalaba el senador Ricardo González, miembro informante de la minoría, que la "modificación parcial de algunos artículos del proyecto" no era suficiente para que se realizara una "modificación de fondo." 44

Los principales aspectos de disidencia tenían que ver en primer lugar, con la posición respecto al poder eclesiástico, en segundolugar con la utilización de la escuela como vía de difusión de la cultura política oficial y en tercer lugar con la subordinación de la comunidad educativa que significaba para la oposición el reemplazo de los Consejos Escolares de Distrito por Delegaciones Administrativas. El eje de la crítica al proyecto se centró en el calificativo de totalitaria, utilizado también para referir a otros aspectos del gobierno. En palabras del senador Ricardo González, se trataba de "una ley totalitaria, clerical y peronista que lleva a la pretensión de deformar para siempre la escuela argentina." 45

La defensa del oficialismo consistió en caracterizar a la ley como "Católica, Argentina y con sentido nacional". Particularmente el cuestionamiento al calificativo de totalitaria, fue el que se desarrolló en mayores oportunidades, incluso en la presentación del proyecto en el Senado, anteponiéndose a la crítica de la oposición. En la fundamentación, el senador Ángel Siri miembro informante del oficialismo, preguntaba a la oposición, "si puede calificarse de totalitaria una ley que comienza por establecer en su artículo dos que corresponde a la familia el derecho inalienable y el deber ineludible de educar a sus hijos, y en virtud de ello, tiene la libertad de elegir las personas o instituciones donde hayan de recibir educación primaria." ${ }^{46}$

La dinámica de las discusiones estuvo determinada no solo por las discrepancias respecto al nuevo proyecto sino por las distintas concepciones en torno a la hasta entonces vigente Ley de Educación Común. El argumento del oficialismo consistió en que la Ley de 1875 se basaba en una concepción de la educación, la vieja educación liberal, diferente a la que ellos proponían y que si bien para su tiempo era muy adecuada, no lo era en la actualidad, tratándose de un "vetusto instrumento legal derogado de hecho por el transcurso de los años y la modificación de la fisonomía del país". ${ }^{47}$ Además de considerarla una ordenación administrativa de la Dirección General deEscuelas, caracterizaron a la Ley comoenciclopedista y neutra. La oposición, en cambio, a pesar de reconocer la posibilidad de superación del orden educacional, mantenía como proyecto el resguardo de la educación liberal democrática y los valores culturales tradicionales que el peronismo vulneraba. ${ }^{48}$

En la Cámara de Senadores, luego de participar en el debate general, la oposición votó en contra del proyecto y se abstuvo en la discusión particular. En la Cámara de Diputados, en cambio, se retiró del recinto antes de la votación dando así muestra de que la consideraban una ley ilegítima. Finalmente con mayoría oficialista, el 14 de agosto de 1951 fue sancionada la nueva Ley de Educación, con el número 5650. Quedó estructurada en cuatro partes que referían a los fundamentos de la educación

\footnotetext{
44 Provincia de Buenos Aires, Diario de Sesiones de la Cámara de Senadores, ([en adelante PBADSCS], 1951), 340.

45 PBADSCS, 1951, 318.

46 PBADSCS, 1951, 316

47 PBADSCS, 1951, 317

48 PBADSCS, 1951, 318
} 
primaria; la organización y planes de estudio de escuelas primarias; la enseñanza preescolar, postescolar y orientación vocacional y la función de escuela, asistencia a alumnos y derechos y obligaciones de docentes.

El texto de la ley se mantuvo sin modificaciones hasta junio de 1955. En el marco del conflicto entre el peronismo y la Iglesia católica, la legislatura bonaerense suprimió el artículo noveno que establecía la enseñanza católica y reformó la redacción de aquellos que referían a la misma (Ley № 5823/55). ${ }^{49}$ Sin embargo, se mantuvieron aquellas medidas realizadas por iniciativa de la Iglesia, como la supresión de la educación preescolar y la división de los niños en escuelas según el género.

Apenas producido el Golpe de Estado que derrocó al peronismo, el gobierno de turno comenzó a borrar los símbolos peronistas, desacreditando la figura de Perón y de diversos funcionarios pertenecientes a todos los niveles estatales. Si reparamos en la normativa, encontramos que se dictaron desde un primer momento una serie de disposiciones tendientes a eliminar todas aquellas referencias que de forma gráfica, escrita u oral hicieran mención al gobierno peronista, cuya regla culminante fue la sanción del famoso Decreto 4161/56 que prohibía en todo el territorio de la Nación "la utilización con fines de afirmación ideológica peronista... de las imágenes, símbolos, signos, expresiones significativas, doctrinas, artículos y obras artísticas, que pretendan tal carácter o pudieran ser tenidas por alguien como tales..." Estas políticas de carácter pedagógico y represivo estuvieron destinadas a desmitificar al peronismo con el objetivo de reeducar al soberano.$^{50}$ En este sentido la educación escolar ocupaba un lugar fundamental.

Sin embargo, más allá del plan de desperonización propuesto por la gestión de la autoproclamada "Revolución Libertadora" y las transformaciones en los programas y contenidos escolares, luego de 1955 se mantuvieron varios aspectos de la política educativa del peronismo. ${ }^{51}$ En lo que respecta a la Ley de Educación, que aquí nos interesa, solo fueron suprimidos o reformados los conceptos que hacían referencia a la doctrina peronista. Específicamente, el Decreto Ley 423, firmado en octubre de 1955, eliminó algunos párrafos del primer artículo sobre la concepción de la educación y la parte del artículo 11 que establecía que "El estudio de las constituciones nacional y provincial se hará en base a la doctrina político social que las informa" por "en base a una doctrina que se fundamente en los principios auténticos de la Historia Argentina". ${ }^{52}$

49 Esta reforma no se trató de un hecho aislado. Por el contrario, a nivel nacional, a fines de 1954 se dispuso la supresión de la Dirección e Inspección General de Enseñanza Religiosa, poco tiempo después el Ministerio de Educación de la Nación eliminó la necesidad de promoción en la materia de Religión y en mayo de 1955 fue derogada en el Congreso Nacional la Ley de Enseñanza Religiosa (Ley No 14.401/55).

50 Estela Spinelli Los vencedores vencidos. El antiperonismo y la "Revolución Libertadora" (Buenos Aires: Biblos, 2005), 66.

51 El diseño institucional del gobierno educativo se mantuvo a lo largo de estos años. En la provincia de Buenos Aires entre 1955 y 1958 el Ministerio de Educación mantuvo la estructura construida durante el peronismo y recién a fines de 1958 se incorporaron los consejos escolares y se reformó el Reglamento General de Escuelas. Ver Mara Petitti La educación primaria en tiempos de la "Revolución Libertadora": el caso de la provincia de Buenos Aires (1955-1958) Revista Quinto Sol, 18, No. 1 (2014).

52 Decreto 423 del 18 de octubre de 1955. Véase Anales de la Legislación Argentina, 1955. p. 1200. Se eliminaron párrafos de los incisos b, c y d del artículo primero. del inciso b: “... tendientes a que su obra personal, familiar y social sean conforme a los principios de la Doctrina Nacional." Del inciso c: “... y que ese bien común argentino se legrará con la realización de la Justicia Social, para lo cual la Nación Argentina deberá ser políticamente independiente de los imperialismos y económicamente libre de las organizaciones capitalistas supranacionales, que durante muchas décadas de su historia la tuvieron sojuzgada.” Del inciso d: “... y la convicción de que el afianzamiento de los postulados más arriba enunciados dentro de la orbe de la civilización occidental conforma la misión 
Durante el gobierno militar proclamado en septiembre de 1955, poco tiempo después que fuera invalidada la Constitución Nacional de 1949, las provincias derogaron las constituciones sancionadas durante el peronismo. En el caso de Buenos Aires el interventor Emilio Bonnecarrére, dispuso que desde el 16 de mayo de 1956 rigiera nuevamente la Constitución de 1934 que como hemos dicho, establecía que el gobierno y la administración escolar debían estar en manos de la Dirección General de Escuelas, el Consejo General de Educación y los Consejos Escolares. ${ }^{53}$

El hecho de que la Ley de Educación solo fuera modificada en aquellas menciones que explicitaban la doctrina peronista - en lugar de ser reemplazada por aquella de 1875-, llama la atención teniendo en cuenta que los partidos políticos que se opusieron a su sanción participaron en la toma de decisiones políticas posteriormente a 1955 y que la restauración de la Constitución de 1934 habilitaba la adecuación de la Ley de Educación a su texto. Al igual que a nivel nacional, pero dos meses después (en enero de 1956) en la provincia de Buenos Aires el Poder Ejecutivo conformó una Junta Consultiva para someter a consulta proyectos del Poder Ejecutivo y pronunciarse sobre ciertos asuntos para ponerlos en consideración. Estuvo integrada por representantes del Partido Demócrata Progresista, conservadores, de la Unión Cívica Radical del Partido Demócrata Cristiano y del Partido Socialista.

Como ha señalado Spinelli, las diferencias existentes en el interior de la coalición antiperonista fueron profundas y chocaron entre sí, impidiendo la constitución de un frente político e imposibilitando las bases de un acuerdo partidario. ${ }^{54}$ Los distintos posicionamientos ante el peronismo, tuvieron como resultado la fractura de la Unión Cívica Radical, en Unión Cívica Radical Intransigente (UCRI) y Unión Cívica Radical del Pueblo (UCRP). Las dimensiones electorales de cada partido fueron medidas en el entonces llamado "recuento globular." Tal como ha evidenciado Julio Melon la concurrencia en las urnas de los peronistas proscriptos junto a la UCRI, a través del conocido como Pacto Perón Frondizi, se debió a que esa alianza era más factible que un frente que contuviera la diversidad de los partidos antiperonistas. ${ }^{55}$

El triunfo de la UCRI en las elecciones de febrero de 1958 que llevaron a Arturo Frondizi a la presidencia de la nación, en la provincia de Buenos Aires dio por ganadora a la fórmula que encabezaba Óscar Alende, quien contaría hasta 1960 con la mayoría simple en la Cámara de Diputados, mientras que la minoría quedó conformada por la UCRP y el Partido Socialista. El retorno de un gobierno democrático aunque con el peronismo proscripto llevaba a la necesidad de reformar la Ley de Educación para adaptarla a la Constitución provincial de 1934, que entre otras cuestiones, implicaba la restauración de la Dirección General de Escuelas, el Consejo General de Educación y los Consejos Escolares. Si bien se presentaron tres proyectos con ese fin, ninguno llegó a ser discutido en la legislatura.

histórica que la República Argentina debe cumplir."

53 Decreto 7.565, Registro Oficial de la Provincia de Buenos Aires, 16 de mayo de 1956.

54 Estela Spinelli Los vencedores vencidos. El antiperonismo y la "Revolución Libertadora" (Buenos Aires: Biblos, 2005): 131-132.

55 Julio Melon Pirro, El peronismo después del peronismo. Resistencia, sindicalismo y política luego del 55 (Buenos Aires: Siglo XXI, 2009): 229-230. 
El oficialismo planteaba la coexistencia del Ministerio de Educación con la Dirección General de Escuelas y no explicitaba la restauración del Consejo General de Educación, a la vez que introducía al textola enseñanza dela religión católica en horario de clase. Ese proyecto fue duramente criticado por la oposición y en octubre de 1959 la UCRP presentó otro como despacho en disidencia, que entre las cuestiones centrales, establecía la neutralidad de la educación en lo político y en lo religioso y jerarquizaba las atribuciones de los Consejos Escolares de Distrito, la Dirección General de Escuelas y el Consejo General de Educación..$^{56}$ Proponía dividir el presupuesto del Ministerio entregando a la Dirección General de Escuelas todos los recursos destinados a la enseñanza primaria en su organización administrativa y técnica, dándole la autarquía económica, y propiciar una ley que reglamentara la enseñanza secundaria y superior bajo la superintendencia del Ministerio de Educación. ${ }^{57}$

Unos meses después, teniendo en cuenta que la comisión de Instrucción Pública no había comenzado a estudiar los proyectos, el diputado Néstor Picadoen representación del bloque de la UCRP, se preguntaba por las razones por las cuáles no se había puesto en vigencia la Ley de Educación de 1875 "que reglamentaba todo el mecanismo escolar, cuyo valor doctrinario ha sido reconocido a través de una experiencia de más de medio siglo." Agregaba que el proyecto presentado por la UCRI adolecía de graves fallas y no la superaba teóricamente..$^{58}$

En mayo de 1960 el bloque socialista presentó un nuevo proyecto, según el cual, el Ministerio de Educación tenía que ser suprimido. ${ }^{59}$ Los legisladores del Partido Socialista, señalaban que la reforma realizada en octubre de 1955 por el gobierno de la "Revolución Libertadora", había constituido un "remedio imprescindible para salir del paso", pero no podía mantenerse más: "La ley 5650 tiene notorias deficiencias; se trata, en general, de un texto farragoso, que nada dice." Pero a la vez argumentaban que no se podía volver a la ley de 1875 "Durante la intervención o en los primeros meses del actual gobierno, se podría haber aceptado la reposición de la ley de 1875, con algunas reformas que la actualizaran, hasta tanto se dictara una nueva ley en su reemplazo." Sin embargo, agregaba, en ese contexto "con todos los méritos que tuvo la Ley de 1875, en casi un siglo que ha corrido desde su sanción, ha quedado forzosamente retrasada. Muchas de sus disposiciones carecerían hoy de eficacia en razón de los cambios operados y no permitirían encarar en toda su profundidad y extensión los nuevos problemas de enseñanza." 60

En el mes de septiembre de 1960, la UCRP presentó una manifestación para que la comisión emitiera su despacho y sometió a consideración de la Cámara de Diputados la posibilidad de acordar un plazo, teniendo en cuenta que había trascurrido el tiempo reglamentario. Sin embargo, argumentando la importancia que revestía su sanción, la UCRI no apoyó ese pedido. ${ }^{61} \mathrm{Si}$ bien no se produjo el despacho de las comisiones,

\footnotetext{
56 PBADSCD, 1959, 1762-1770.

57 PBADSCD, 1960, 2784.

58 PBADSCD, 1960, 2768-2790.

59 PBADSCD, 1960, 121-148 y PBADSCD, 1960, 2785.

60 PBADSCD, 1960,140.

61 PBADSCD, 1960, 1208
} 
las principales cuestiones en las cuales no existió acuerdo para tratarse la Ley de Educación, fueron debatidas en el marco de otros proyectos relacionados. Por un lado, la ampliación de las atribuciones de los Consejos Escolares y por otro, la solicitud de informes acerca de la enseñanza de religión católica en las escuelas.

En enero de 1960, al discutirse el proyecto de Ley Orgánica de Consejos Escolares, el diputado de la UCRP Néstor Picado, señaló que estando vigente la Constitución de 1934 era inexplicable que "la intervención nacional haya dejado la estructura que la Constitución de la provincia de 1949 había implantado, para hacer desaparecer toda la organización que habían establecido las constituciones de 1873, 1889 y 1934 y que reglamentó la Ley de Educación de 1875 y con ello, los Consejos Escolares, organismos de esencia republicana pura." 62

El argumento constitucionalista no era exclusivo del sector minoritario, ya que al debatirse la introducción de contenidos de moral en las escuelas, era la UCRI la que se basaba en la Carta Magna para justificar la medida. Sobre esta base, apenas un mes después de asumido el gobierno de Óscar All ende, y previamente a que se desatara el conflicto entre la enseñanza libre o laica, el Ministerio de Educación emitió una resolución que establecía la aplicación de la enseñanza de moral y religión, lo cual motivó el reclamo por parte de los partidos políticos opositores. ${ }^{63}$

Al día siguiente el bloque socialista, apoyado por el sector de la UCRP, presentó un proyecto de solicitud de informes y consiguió que se aprobase la presencia del ministro de Educación, en la cámara de diputados para dar explicaciones respecto a dicha resolución. ${ }^{64}$ Además de mencionar diversos antecedentes respecto a la tradición laicista del radicalismo, los socialistas cuestionaron particularmente el cambio de parecer por parte del ministro de Educación, refiriendo que en su actuación como diputado provincial durante el peronismo, se había opuesto a la introducción de la enseñanza religiosa en la Ley de Educación de $1951 .^{65}$ Luego de un extenso debate, la oposición encontró un argumento que conciliaba la situación. Si seguía la normativa al pie de la letra, era el Consejo General de Educación [aún no restituido] y no el ministro quien debía encargarse del estudio de los programas. ${ }^{66}$ Se resolvió la suspensión transitoria de la aplicación del artículo más conflictivo mediante una nueva resolución, a los efectos de que el Poder Legislativo dictara una ley que englobara en sus disposiciones la solución de todos los problemas relativos a la organización de la educación en la Provincia. ${ }^{67}$

La Ley de Educación de 1951, se mantuvo vigente hasta 1995. A lo largo de ese periodo, se efectuaron alteraciones en la estructura del gobierno de la educación que no fueron introducidas a su texto.$^{68}$ Por otra parte, se realizaron reformas parciales que

62 PBADSCD, 1960, 2783.

63 PBADSCD 1958, 492-494, 643-648. Sobre el conflicto entre la enseñanza libre o laica, ver Valeria Manzano "La batalla de los laicos: movilización estudiantil en Buenos Aires, septiembre- octubre de 1958" en Boletín del Instituto de Historia Argentina y Americana Dr. Emilio Ravignani, tercera serie, No. 31, 2009.

64 Proyecto de solicitud de informes, PBADSCD 1958, p. 492-494.

65 PBADSCD 1958, 643.

66 PBADSCD 1958, 666.

67 PBADSCD 1958, 678.

68 Entre 1958 y 1964 la Dirección General de Escuelas convivió con el Ministerio de Educación, estando ambos organismo a cargo de 
no afectaron los lineamientos generales de la normativa. Además de la Ley 5823 y el Decreto 423 de 1955 ya mencionados, en 1972 se modificaron dos artículos respecto a la participación de padres y vecinos y a las organizaciones docentes. ${ }^{69}$ Por otra parte, en 1973 se oficializaron los establecimientos municipales y aquellos pertenecientes a la Iglesia Católica; en 1976 se suspendió por 180 días el artículo 29 sobre la organización gremial de los docentes y en 1987 se amplió un año la obligatoriedad de la educación, incorporándose el preescolar para los niños de cinco años. ${ }^{70}$

En 1995, poco después de que finalizara la transferencia o provincialización de las escuelas nacionales de nivel secundario, técnico y de los institutos de formación, la provincia de Buenos Aires sancionó la Ley de Educación 11.612. La misma legislaba acerca de los derechos, obligaciones y garantías; los principios de la educación; el sistema educativo; la gratuidad y el asistencialismo; las unidades educativas; la comunidad educativa; los derechos y deberes de los miembros de la comunidad educativa; la calidad de la educación y su evaluación; el gobierno y administración -el más amplio-; la gestión privada y el patrimonio y los recursos.

Solo los conceptos utilizados -asistencialismo, calidad, evaluación, gestión privadadan cuenta de un nuevo cambio en el objeto de la legislación. La transformación educativa que tuvo lugar en los años ‘ 90 se inscribe en el proceso de reforma del Estado, descentralización, privatización del espacio público y desregulación de los servicios sociales que se llevó a cabo en la mayor parte de los países de América Latina. ${ }^{71}$ En 1993, luego de un complejo proceso legislativo, se sancionó la Ley Federal de Educación que introdujo profundas transformaciones en la estructura educativa que quebraba con la tradicional organización en educación primaria y secundaria; extendió a 10 años la obligatoriedad escolar; definió los Contenidos Básicos Comunes; implementó un Sistema Nacional de Evaluación de la Calidad y otorgó un papel subsidiario al Estado, que quedó encargado de favorecer el desarrollo del sector privado."72

La Ley de Educación de la provincia adecuó a los requerimientos de la Ley Federal de Educación, incluyendo la estructura de Educación General Básica, obligatoria, de nueve años de duración a partir de los seis años de edad y Polimodal, de tres años

un mismo funcionario. En 1964, durante el gobierno de la UCRP se sancionó la Ley 6749 que además de diferenciar las funciones de la Dirección General de Escuelas respecto a las del Ministerio de Educación, restauró el Consejo General de Educación. Dicha normativa fue derogada en 1966 a partir de lo cual el Ministerio de Educación quedó a cargo de la totalidad de la enseñanza provincial. En 1984 la Dirección General de Escuelas y Cultura y el Consejero General de Educación y Cultura, reemplazaron al Ministerio de Educación. En 1994 con la reforma constitucional, la Dirección General de Escuelas y Cultura cambió su denominación por Dirección General de Cultura y Educación, con rango ministerial la cual se mantiene hasta hoy en día.

69 Ley 7923 modificó el artículo 30 respecto a la participación de los padres y vecinos, en el cual se eliminó la obligación de concurrir a prestar la colaboración a las escuelas y a los docentes para el mejor cumplimiento de los fines expuestos por la presente e incorpora el reconocimiento a las entidades co-escolares de la atribución de participar de la co-gestión en materia de cooperación escolar. La Ley 7926 modificó el artículo 29 sobre la organización libre de los docentes en entidades, eliminando entre los motivos de organización los intereses gremiales y la posibilidad de obtener personería civil y gremial. Ver Ley 7923, Registro Oficial de la provincia de Buenos Aires, 4 de septiembre de 1972 y Ley 7926, Registro Oficial de la provincia de Buenos Aires, 7 de septiembre de 1972.

70 Véase Decreto 921/73, Registro Oficial de la Provincia de Buenos Aires, 12 de marzo de 1973; Decreto-Ley 8617, Registro Oficial de la Provincia de Buenos Aires, 20 de julio de 1976 y Ley 10.610, Registro Oficial de la Provincia de Buenos Aires, 3 de diciembre de 1989.

71 Ver Pablo Gentile, et. al. Políticas de privatización, espacio público y educación en América Latina. (Rosario: Homo Sapiens Ediciones, 2009).

72 Ver Myriam Feldfeber y Nora Gluz "Las políticas educativas en argentina: herencias de los '90, contradicciones y tendencias de "nuevo signo" En Educ. Soc., Campinas, Vol. 32, (115), 339-356, 2011 y Norma Paviglianiti, "La Ley Federal de Educación como elemento de regulación de la realidad socioeducacional en la Argentina" en Segundo Encuentro Internacional "La educación y el Mercosur." Porto Alegre, agosto, 1993. 
de duración después de cumplida la Educación General Básica. Adoptó una política educativa sumamente centralizada e impuesta "desde arriba hacia abajo" y estableció el asistencialismo como uno de los principios del sistema educativo. ${ }^{73}$

\section{CONCLUSIÓN}

El Golpe de Estado de 1955, que ha sido tomado como un punto de quiebre en la periodización de la historia de la educación argentina, no significó una modificación en la Ley de Educación de la provincia de Buenos Aires sancionada durante el primer peronismo. Esto llama la atención además, teniendo en cuenta que los partidos políticos que se habían opuesto a su sanción, a partir del 16 de septiembre de 1955 pasaron a constituir parte del gobierno. Ahora bien, ¿por qué no se reformó la Ley de Educación durante los años de la "Libertadora", así como tampoco durante el gobierno constitucional de Óscar Alende? Para responder este interrogante, a lo largo del artículo realizamos un recorrido histórico de la Ley de Educación de la provincia de Buenos Aires entre su sanción en 1875 y la reforma de 1995.

Consideramos que la continuidad de la normativa aprobada en 1951 expresa que era difícil volver atrás en relación a los cambios que se habían producido en la configuración escolar. En este sentido puede comprenderse que al debatirse el proyecto de ley, más allá de las ideas peronizantes y católicas, puntos centrales de la crítica que respondieron a una coyuntura determinada y que fueron eliminados en 1955, no encontramos reparos por parte de la oposición respecto al contenido de la legislación. Con la Ley de 1951 se institucionalizaba un cambio en el concepto de educación, un concepto que incorporaba la enseñanza postescolar y especial, así como también los aspectos concernientes al ámbito cultural. La normativa dejó de regular sobre el gobierno de la educación y los recursos, para pasar a hacerlo sobre aspectos referidos a los contenidos y los nuevos actores de la educación. En este sentido podemos decir que el objeto de la legislación se modificó. Por el contrario, los cambios parciales o proyectos de reforma relativos a la Ley de 1875 que se realizaron hasta 1951 no afectaron las cuestiones a ser legisladas.

En la segunda parte, hemos profundizado en los intentos de reforma del periodo 1958-1962 y la dificultad de encontrar un acuerdo. Nuevamente, al igual que en el periodo anterior, los puntos conflictivos no afectaban la estructura de la Ley ni pretendían legislar a partir de cambios en su aplicación, sino que por el contrario se proponían modificar la organización del gobierno de la educación y los aspectos concernientes a la enseñanza de la religión. Recién en 1995 fue reemplazada por otra, en el marco del proceso de reforma del Estado, descentralización, privatización del espacio público y desregulación de los servicios sociales.

Podemos afirmar por lo tanto, que la sanción de la Ley de Educación de la provincia de Buenos Aires en 1875, 1951 y 1995 coinciden con los momentos instituyentes

73 Gorostiaga, Jorge, Acedo, Clementina y Senén González, Smilvia, “¿Equidad y calidad en el tercer ciclo de la educación general básica? El caso de la provincia de Buenos Aires” REICE. Revista Electrónica Iberoamericana, 1, No. 2 (2004). 
propuestos por Patricia Berrotarán y Elsa Pereyra en un texto citado al comienzo de este trabajo, que pretende realizar una periodización del Estado argentino diferente a la tradicional. Siguiendo esta línea es posible plantear la coincidencia entre el cuarto momento instituyente que sugieren las autoras a partir de 2003 con la reinstauración de la política y el estado "como recursos nuevamente activos y con discurso propio" y la última reforma a la Ley de Educación (№ 13.688) efectuada en el año 2007.

En suma, observamos que las reformas a la Ley concordaron con cambios profundos en los objetos de legislación que se dieron en el marco de transformaciones en el Estado argentino. Por lo tanto, concluimos que es posible cuestionar los alcances de tomar el derrocamiento del gobierno peronista en 1955 como un punto de quiebre en la periodización de la Historia de la Educación Argentina.

\section{FUENTES}

Anónimo, "Severa crítica al proyectado Estatuto del Docente hizo el diputado Bronzini." El Trabajo, Mar del Plata 2 de julio, 1951.

Anónimo. "Una Ley de Educación." La Nación, Ciudad de Buenos Aires, 17 de julio, 1951.

Constitución de la Nación Argentina 1853.

Constitución de la provincia de Buenos Aires, 1873, 1934, 1949.

Decreto-Ley 7.565/56. Restitución de la Constitución de 1934.

Decreto 423 del 18 de octubre de 1955. Véase Anales de la Legislación Argentina, 1955. p. 1200.

Ley 5823/55. Modificatoria de la Ley 5650 de Educación, en lo referente a la enseñanza de la religión. Registro Oficial de la provincia de Buenos Aires, 14 de junio de 1955. En línea: http://www.gob.gba.gov.ar/intranet/digesto/PDF/15823.pdf

Ley 988. Ley de Educación Común. Registro Oficial de la provincia de Buenos Aires, 6 de septiembre de 1875.

Ley 5650. Ley de Educación. Registro Oficial de la provincia de Buenos Aires, 20 de agosto de 1951.

Ley 11.612. Ley provincial de Educación. Registro Oficial de la provincia de Buenos Aires, 12 de enero de 1995.

Ley 13.688. Ley provincial de Educación. Registro Oficial de la provincia de Buenos Aires 5 de julio de 2007.

Provincia de Buenos Aires, Diario de Sesiones de la Cámara de Diputados, La Plata. Años 1874, 1905, 1951, 1952, 1958, 1959 y 1960.

Provincia de Buenos Aires, Diario de Sesiones de la Cámara de Diputados, La Plata. Año 1951. 
Anteproyecto de Ley Orgánica de Educación Común. En Boletín Oficial de Educación. Abril de 1946, año 9, número 79, Dirección General de Escuelas de la provincia de Buenos Aires, La Plata.

Revista de Instrucción Primaria, 1946, mayo, 15.

Revista de Instrucción Primaria, 1944, octubre, 16.

Reglamento General para las Escuelas Públicas, vigente desde el 1 de septiembre de 1944, La Plata, Taller de Impresiones Oficiales, 1944.

\section{REFERENCIAS}

Acha, Omar y Quiroga Nicolás. El hecho maldito. Conversaciones para otra historia del peronismo, Rosario: Prohistoria, 2012.

Aelo, Oscar. El peronismo en la provincia de Buenos Aires (1946-1955), Caseros: Eduntref, 2012.

Adúriz Bravo, Agustín. "Hacia la especificidad de la historia de la educación en un abordaje transdisciplinar." Revista Latinoamericana de Estudios Educativos (México), vol. XXXI, (2), (2001): 59-68.

Avalo Viamontes, Vilfredo "Evolución de la escuela rural en Cuba en los siglos XIX y XX" en Revista historia de la educación latinoamericana, 18, No. 26, (2016): 91-112.

Barba, Enrique "La ley de educación común de Buenos Aires de 1875", en Trabajos y Comunicaciones, 18 (1968): 53-65.

Béjar, María Dolores. "Altares y banderas en una educación popular: la propuesta del gobierno de Manuel Fresco en la provincia de Buenos Aires (1936-1940)" en Mitos, altares y fantasmas. Aspectos ideológicos de la historia del nacionalismo popular. Estudios/Investigaciones núm. 12. Universidad Nacional de La Plata, 1992.

Berrotarán, Patricia y Pereyra, Elsa "Momentos y Procesos para una historia del Estado en Argentina", Revista Aportes para el Estado y la administración gubernamental. Buenos Aires, 18, No. 30 (2012).

Braslavsky Cecilia La educación argentina (1955-1980). Buenos Aires: CEAL, 1980.

Carli, Sandra. Niñez, pedagogía y política. Transformaciones de los discursos acerca de la infancia en la historia de la educación argentina entre 1880 y 1955. Buenos Aires: Miño y Dávila, 2002.

Castillo Silvia "Las políticas y las prácticas educativas del magisterio pampeano (19581966)" Tesis de Doctorado. Facultad de Ciencias Humanas, Universidad Nacional del Centro, 2013.

Chiaramonte, Carlos. “La historia intelectual y el riesgo de las periodizaciones". Prismas, Revista de historia intelectual, No. 11, (2007): 189-193.

Cuccuza Rubén "Continuidades y rupturas el problema de las periodizaciones", Anuario SAHE, No.1, 1996. 
Cucuzza Rubén (dir.) y Pineau Pablo (codir.). Para una historia de la enseñanza de la lectura y escritura en Argentina. Del catecismo colonial a La Razón de mi Vida. Buenos Aires: Miño y Dávila, 2002.

Da Orden, María Liliana y Regalsky, Andrés. "Fiscalidad y organización estatal en la provincia de Buenos Aires (1880-1943)." En Historia de la provincia de Buenos Aires. Tomo IV. De la federalización de Buenos Aires al advenimiento del peronismo, editado por Manuel Palacio. Buenos Aires: Edhasa, 2013.

De Luca, Romina. Brutos y Baratos. Descentralización y privatización en la educación argentina (1955-2001) Buenos Aires: ediciones RyR, 2008.

Feldfeber, Myriam y Gluz, Nora. "Las políticas educativas en argentina: herencias de los '90, contradicciones y tendencias de "nuevo signo" Educ. Soc., Campinas, 32, No.115 (2011): 339-356.

Gorostiaga, Jorge; Acedo, Clementina y Senén González, Silvia. “¿Equidad y calidad en el Tercer Ciclo de la Educación General Básica? El caso de la Provincia de Buenos Aires" Revista Electrónica Iberoamericana sobre Calidad, Eficacia y Cambio en Educación, 2, No. 1, (2004) Disponible en http://www.ice.deusto.es/rinace/reice/ vol2nl/Gorostiaga.pdf.

Gutiérrez, Talía. Educación, agro y sociedad; políticas educativas agrarias en la región pampeana, 1897-1955 Buenos Aires: Universidad Nacional de Quilmes, 2007.

Lionetti, Lucía. La misión política de la escuela pública. Formar a los ciudadanos de la república (1870-1916) Buenos Aires: Miño y Dávila, 2007.

Narodowski, Mariano. “La utilización de periodizaciones macropolíticas en la historia de la educación. Algunos problemas", en Escuela, historia y poder. Miradas desde América Latina, editado por Martínez Boom y Mariano Narodowski. Buenos Aires: Novedades Educativas, 1996.

Manzano Valeria "La batalla de los laicos: movilización estudiantil en Buenos Aires, septiembre- octubre de 1958." Boletín del Instituto de Historia Argentina y Americana Dr. Emilio Ravignani, tercera serie, No. 31 (2009).

Melon Pirro, Julio. El peronismo después del peronismo. Resistencia, sindicalismo y política luego del 55. Buenos Aires: Siglo XXI, 2009.

Palacio, Juan Manuel "Prólogo", Historia de la provincia de Buenos Aires. De la federalización de Buenos Aires al advenimiento del peronismo (1880-1943). La Plata: Edhasa, 2013, 9.

Paviglianiti, Norma "La Ley Federal de Educación como elemento de regulación de la realidad socioeducacional en la Argentina" en Segundo Encuentro Internacional "La educación y el Mercosur." Porto Alegre, agosto, 1993.

Pineau, Pablo. La escolarización de la provincia de Buenos Aires (1875-1930), Buenos Aires: Universidad de Buenos Aires, FLACSO, 1997.

Pinkasz, Daniel. "Escuelas y desiertos: hacia una historia de la educación primaria de la provincia de Buenos Aires." En Historia de la Educación en las Provincias y Territorios Nacionales. (1885-1945), editado por Adriana Puiggrós Buenos Aires: Galerna, 1993. 
Puiggrós, Adriana (dir.). Dictaduras y utopías en la historia reciente de la educación argentina (1955-1983). Buenos Aires: Editorial Galerna, 1997.

Rein, Mónica Politics and Education in Argentina, 1946-1962. Nueva York: M.E. Sharpe, 1998.

Rockwell, Elsie. Hacer escuela, hacer estado. La educación posrevolucionaria vista desde Tlaxcala. México: CIESAS, 2007.

Sebastiani, Marcela García. “La otra cara de la Argentina peronista: radicales y socialistas en la oposición política a Perón (1946-1955). En Fascismo y antifascismo peronismo y antiperonismo. Conflictos políticos e ideológicos en la Argentina (1930-1955), editado por Marcela García Sebastiani. Madrid/Frankfurt: Vervuert, 2006.

Smeja, Marina y Téllez, Magaldy. “Una mirada crítica a las prácticas discursivas dominantes en el campo de la historia de la educación en Venezuela", en Escuela, historia y poder. Miradas desde América Latina, editado por Martínez Boom y Mariano Narodowski. Buenos Aires: Ediciones Novedades Educativas, 1996.

Southwell, Myriam "Algunas características de la formación docente (1955- 1976)." En Dictaduras y utopías en la historia reciente de la educación argentina (1955- 1983), editado por Adriana Puiggrós. Buenos Aires: Editorial Galerna, 1997.

Spinelli, Estela. Los vencedores vencidos. El antiperonismo y la "Revolución Libertadora", Buenos Aires: Biblos, 2005.

Tedesco, Juan Carlos. Educación y sociedad en la Argentina (1880-1945) Buenos Aires: Siglo Veintiuno, 2003.

Ternavasio, Marcela "Municipio y política, un vínculo histórico conflictivo. La cuestión municipal en Argentina entre 1850 y 1920." Tesis de Maestría, FLACSO, Buenos Aires, Argentina, 1991. Disponible en http://sala.clacso.org.ar/ [último acceso: marzo 2007].

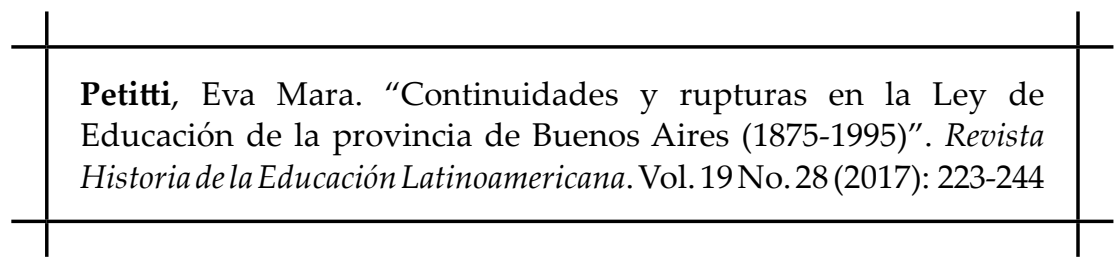

